\title{
Numerical Simulation of Fluidized Dense-Phase Pneumatic Conveying of Powders towards Developing Improved Model for Solids Friction Factor
}

\author{
Baldeep Kaur $^{1}$, Anu Mittal ${ }^{2 *}$, S.S.Mallick ${ }^{2}$, Renhu Pan $^{3}$ and Soumendu Jana ${ }^{1}$ \\ ${ }^{1}$ School of Physics and Materials Science, Thapar University, Patiala, Punjab-147004, India \\ ${ }^{2}$ Department of Mechanical Engineering, Thapar University, Patiala, Punjab-147004, India \\ ${ }^{3}$ Fujian Longking Co., Ltd., Longyan, Fujian 364000, People's Republic of China
}

*Corresponding author. Email address: anu.mittal@thapar.edu

Telephone number: +91-175-2393080

\begin{abstract}
Fluidized dense-phase pneumatic conveying of fine powders is popular in various industries, such as power, chemical, cement, refinery, alumina, pharmaceutical, limestone etc. due to the reasons of decreased gas flow rate and power consumption, reduced conveying velocities, improved product quality control, smaller pipeline sizes, decreased wear rate, increased workplace safety, etc. It is important to accurately predict solids friction factor through horizontal straight pipes for the reliable design of a pneumatic conveying system. However, accurate modelling of solids friction factor from an improved understanding of the fundamental transport mechanism of fluidized dense-phase flow condition has only made limited progress till now due to the highly concentrated, turbulent and complex nature of the gas-solids mixture. Power stationfly ash (median particle diameter: $22 \mu \mathrm{m}$; particle density: $2370 \mathrm{~kg} / \mathrm{m}^{3}$; loosepoured bulk density: $660 \mathrm{~kg} / \mathrm{m}^{3}$ ) was transported through different pipeline configurations (65 mm I.D. x $254 \mathrm{~m}$ long and 80/100 mm I.D. x $407 \mathrm{~m}$ long pipeline). Governing equations of dense-phase pneumatic conveying system were developed and solved numerically. The results
\end{abstract}


for three different solids and two different air flow rates have shown that the particle and actual gas velocities and the ratio of the two velocities increase in the direction of flow, while reverse trend was found to exist for solids volumetric concentration. The numerical results were compared against the predictions obtained using existing empirical relationships for particle velocity. An existing reliable pure dilute-phase model has been modified for dense-phase flow by incorporating sub-models for particle and actual gas velocities and impact and solids friction factor. The solids friction factor model was validated by using it for scale-up prediction for the total pipeline pressure drops in the longer and larger pipes and by comparing the experimental and predicted pneumatic conveying characteristics for different solids flow rates. The results have shown that the accuracy of prediction is similar (in fact better in certain scale-up cases) when compared to a recently developed two-layer based model. The results demonstrate the importance of incorporating particle and actual gas velocity terms in the model of solids friction factor instead of superficial air velocity. Future work should be carried out to develop reliable experimental techniques for the accurate measurement of particle velocity of fine powders under fluidized dense-phase flow condition.

Keywords: pneumatic conveying, dense-phase, numerical analysis, pressure drop, scale-up validation 


\section{Introduction}

Fluidized dense-phase pneumatic conveying of fine powders offers several advantages over the conventional dilute-phase (or suspension flow), such as the high solids to gas mass ratio, low gas flow requirement (i.e. smaller compressor and savings in operating power), smaller size of pipes and fittings, reduced conveying velocity resulting in lowering of wear rate of pipelines and bends, decreased rate of product attrition, reduced size of solids-gas separation equipment, etc. (Mallick, 2009). As a result, this mode of conveying is being increasingly preferred in several industries, such as coal fired thermal power plants, cement, food, chemical, pharmaceutical, petrochemical plants, etc. In fluidized dense-phase method of transport, the gas velocities are kept sufficiently low (below the saltation velocities). As a result, the conveying takes place in a non-suspension mode, in the form of a moving fluidized bed or non-suspension dunes (Marcus et al., 1990; Behera et al., 2013). Typically, fine powders having good air retention properties, such as fly ash, cement, pulverized coal, etc. are good candidates for fluidized densephase mode of conveying (Pan, 1999; Ratnayake and Datta, 2007). Accurate prediction of the total pipeline pressure drop is an important parameter requiring reliable estimation at the design stage. Total pipeline pressure drop includes pressure losses in horizontal straight pipes, verticals, bends and the loss due to initial acceleration. For a typical long distance pipeline (e.g. the pressure conveying line running from buffer hopper to remote silo in a coal fired thermal power plant - typically 500 to $1000 \mathrm{~m}$ long), the major share of total pipeline pressure drop comes from the losses in the horizontal straight pipes. Over-prediction of pressure drop would cause increased initial and operating costs (due to unnecessary higher conveying velocity and power consumption), whereas, under-prediction of pressure drop would result in reduced material 
transport rate. The pressure drop for solids-gas flow through a straight horizontal pipe can be represented by equation (1), as given by Barth [4]. This representation considers the pressure drops due to the gas and solids phases separately.

$\Delta \mathrm{P}=\left(\left(\lambda_{\mathrm{f}}+\mathrm{m}^{*} \lambda_{\mathrm{s}}\right) \rho_{\mathrm{a}} \mathrm{LV}^{2}\right) / 2 \mathrm{D}$

Weber (1981) used equation (1) for coarse particles in dilute-phase flows. Subsequently, various researchers (Pan and Wypych, 1998; Jones and Williams, 2003; Setia et al., 2015) have employed the same to estimate the pressure drop for the fluidized dense-phase pneumatic transport of fine powders. The main challenge in equation (1) is to accurately model and/or predict solids friction factor, which is a combined representation energy loss due to solids to gas, solids to solids and solids to pipe wall interactions (Mallick, 2009). This is due to the highly turbulent and complex nature of the moving fluidized bed of fine powders (in the form of dunes) under high concentration, which makes it very difficult to link the particle and bulk properties during actual flow conditions. Empirical power function based models have been popularly used over the years by several investigators, such as Pan and Wypych (1998) (using dimensionless numbers, as given by equation 2), due to the limited progress towards fundamentally understanding the transport mechanisms under fluidized dense-phase flow conditions and modelling of solids friction factor. Some researchers, such as Jones and Williams (2003), have used a condensed version of equation (2) considering the value of the exponent ' $c$ ' to be zero. This inherently considers that the typical value of particle density being much larger than the gas density, change in gas density would not affect the flow mechanism. 
$\lambda_{s}=K\left(m^{*}\right)^{a}(F r)^{b}\left(\rho_{a} / \rho_{s}\right)^{c}$

Previous evaluation (Mallick, 2009) has shown that the above modeling formats of solids friction factor can provide grossly inaccurate predictions under significant scale-up conditions of pipeline length and diameter. Recently, some of the authors have provided a new two-layer based model format for solids friction factor (Setia et al., 2016), as represented by equation (3). This model separates the solids friction factor into losses contributed due to the impact and friction between particle to air/particle/pipe-wall and that due to keeping the particles in suspension.

$\lambda_{s}=\tau_{1}\left(K(V L R)^{a}\left(w_{f o} / V\right)^{b}\right)+\tau_{2}\left(\lambda_{s}^{*} C / V+2 \beta_{0} /\left[(C / V) F r^{2}\right]\right)$

In the above model, the first term, $K(V L R)^{a}\left(w_{f o} / V\right)^{b}$, was aimed to represent the dense-phase contribution (Setia et al., 2016). The second term, $\lambda_{s}^{*} C / V+2 \beta_{0} /\left[(C / V) F r^{2}\right]$, represented the dilute-phase contribution (Wypych et al., 1990 and Setia et al., 2016). $\beta_{0}$ is given as $w_{f o} / V$. The dilute-phase portion has been taken from a "pure" dilute-phase model, known as "Weber A4" model (Wypych et al., 1990). This model (Weber A4) has been reported (Wypych et al., 1990) to provide good predictions for dilute-phase flow for different pipeline configurations. The twolayer model format was validated by Setia et al. (2016) for scale-up accuracy for two different fly ash samples, ESP dust and cement under different pipeline conditions (viz. pipe internal diameters of 69,80, $105 \mathrm{~mm}$ and lengths of 168, 254, 407 and $554 \mathrm{~m}$ ). The two-layer model provided better reliable scale-up predictions compared to other previously known models for solids friction factor. However, the authors are still of the view that very little progress has been 
achieved to date towards fundamentally understanding the flow mechanism of fluidized densephase solids-gas transport of fine powders. The existing empirical models (Pan and Wypych, 1998; Jones and Williams, 2003; Setia et al., 2015, 2016) for solids friction factor often use the term "superficial gas velocity", instead of actual gas velocity. Superficial gas velocity can be considered to be an accurate gas velocity representation for dilute-phase flow, where the pipe volume occupied by the particles is minor compared to the rest of the pipe volume available for gas flow. However, for fluidized dense-phase type flows under high solids loading ratio, a considerable portion of the pipe cross-section is occupied by the powders. Therefore, the reduced cross section available for the flow of gas-phase should not be ignored. Also, most of the existing models (e.g. equation 2) do not include particle velocity and only rely on the superficial velocity of the gas. The authors are of the opinion that it would be prudent to include a powder velocity term in the model of solids friction factor. This paper aims at developing and numerically solving governing equations for gas-solids flows under dense-phase condition for particle and actual gas velocities and to develop reliable scale-up validated solids friction factor model with an improved understanding of the solids gas transport mechanism.

\section{Experimental Program}

Power station fly ash was conveyed from fluidized dense- to dilute-phase through pipelines of different lengths and diameters (i.e. 65 mm I.D. $x 254 \mathrm{~m}$ long and80/105 mm I.D. $x 407 \mathrm{~m}$ long step-up pipeline) at the pneumatic conveying test rigs available at Fujian Longking Co., China. 
The fly ash was conveyed with different air and solids mass flow rates. Physical properties of the fly ash and pipeline conditions are given in Table 1.

\section{Table 1}

Schematic diagrams of the test rigs are shown in Figure 1. A rotary screw compressor with air drier and receiver were used having the maximum delivery pressure of $750 \mathrm{kPa}$ and $660 \mathrm{~m}^{3} / \mathrm{hr}$ of Free Air Delivery. A bottom discharge type blow-tank $\left(0.75 \mathrm{~m}^{3}\right.$ empty volume $)$ was used as the feeder. A receiving bin of $2 \mathrm{~m}^{3}$ capacity was installed on top of the blow tank. The blow tank was fitted with bag filters having a reverse pulse jet type cleaning mechanism. Mild steel pipelines of different pipeline diameters and lengths (see Table 1) were used. The test rigs included a $13.4 \mathrm{~m}$ vertical height. All the pipelines had $90^{\circ}$ bends of $1 \mathrm{~m}$ radius of curvature. Static pressure measurement tapping points were strategically placed along the pipeline to measure the total pipeline pressure drop (P1) and static pressures in straight pipe (P2 and P3). The receiver bin and blow tank were supported on shear beam type load cells to provide data for mass flow rates for solids. Air flow rates were obtained using annubars with differential pressure measurement arrangements. Flow control valve was used to change the air mass flow rate to achieve wide ranges of air flow rates. A portable PC compatible data logger was used to record the data coming from load cells, static pressure transducers and air flow meter. Initially, the conveying trials were conducted with medium ranges of air flows. Subsequently, the air flow rate was gradually reduced to the dense-phase regime. The air flow rate was then further reduced till unstable flow condition and eventually pipe blockage appeared. Then the air flow was increased to high velocities to obtain 
complete pneumatic conveying characteristics from fluidized dense-to-dilute-phase region (covering a wide range of air and solids flow rates). Some tests were repeated (generally two to three times) to confirm repeatability of test results. All other required instruments, such as PRV (pressure reducing valve), flow meter, NRV (non-return valve), flow control valve, pressure gauge and load cells (shear beam type) were suitably placed. Calibrations of the transducers, load cells and flow meter were performed using a standardized calibration procedure (Mallick, 2009).

\section{Figure 1}

To determine the fluidized bulk density of fly ash, fluidization and de-aeration tests were carried out. A schematic of the test facility is provided in Figure 2.

\section{Figure 2}

A side channel centrifugal type blower $\left(0.75 \mathrm{~kW}\right.$ and maximum air delivery of $\left.145 \mathrm{~m}^{3} / \mathrm{h}\right)$ was used for supplying air to the fluidization chamber. The air flow rate was varied by using a variable frequency drive attached to the blower. Two rotameters were used in the air line to measure the air flow rate within appropriate flow ranges. A mild steel plenum chamber having $102 \mathrm{~mm}$ of internal diameter and height of $150 \mathrm{~mm}$ was attached to the fluidization column for uniform air distribution. A porous membrane with5 $\mu \mathrm{m}$ porosity was placed between the plenum chamber and fluidizing column. The fluidizing column was fabricated using acrylic tube for 
better visibility of the fluidized bed. Five pressure tappings were installed along the height of the column to measure pressure drop. The bed height was measured by using a centimeter scale attached to the column. A set of manometers were used to measure the pressure at each tapping. A high speed digital camera (60 frames per second capturing speed) was used to visualize the fluidization and de-aeration behavior of powders. The fluidization and de-aeration tests were carried out on different fly ash samples with varying particle sizes, including the powder listed in Table 1. Fluidized bulk density values were obtained from the maximum height achieved (measured by the scale) at the onset of fluidization (i.e. corresponding to minimum fluidization condition). The values of fluidized bulk density $\left(\rho_{f l}\right)$ were obtained by dividing the expanded volume of aerated fly ash by the mass of powders. Ratio of fluidized to loose-poured bulk densities for different fly ash samples are provided in Table 2.

\section{Table 2}

From Table 2, the fluidized bulk density value for the conveyed fly ash sample (fly ash no. 1) is found to be $330 \mathrm{~kg} / \mathrm{m}^{3}$. The ratio of fluidized to loose-poured bulk densities for different fly ash samples are in the range of 0.50 to 0.55 (as per Table 2). Fluidization curve and fluidized bulk density curves for the fly ash sample conveyed are provided in Figures 3 and 4, respectively. The value of fluidized bulk density of fly ash used in this paper corresponds to $88 \mathrm{~mm} / \mathrm{s}$ of superficial air velocity.

\section{Figure 3}




\section{Figure 4}

\section{Numerical modeling for solids gas flow}

For developing the governing equations, the following assumptions have been made:

- The flow is one-dimensional (x-direction, i.e. in the direction of bulk flow).

- The composition of solids-gas mixture in a finitely small control volume is uniform and there is no concentration gradient of particles across the pipe diameter.

- The flow is steady.

- The system is isothermal and the gas phase obeys the ideal gas equation of state.

- There is no mass and heat transfer between the phases.

For developing the energy equation, energy balance across a control volume is as given below:

\section{Figure 5}

Along x-direction, the resultant accumulation of pressure and shear energy:

$=A P u_{a}-A\left[\left(P+\frac{d P}{d x} \Delta x\right)\left(u_{a}+\frac{d u_{a}}{d x} \Delta x\right)\right]-\left[F_{a}\left(u_{a}+\frac{d u_{a}}{d x} \frac{\Delta x}{2}\right)+F_{s}\left(u_{s}+\frac{d u_{s}}{d x} \frac{\Delta x}{2}\right)\right]$

Along $\mathrm{x}$-direction, the resultant accumulation of kinetic energy:

$=\frac{1}{2} m_{a} u_{a}^{2}+\frac{1}{2} m_{s} u_{s}^{2}-\frac{1}{2} m_{a}\left(u_{a}+\frac{d u_{a}}{d x} \Delta x\right)^{2}-\frac{1}{2} m_{s}\left(u_{s}+\frac{d u_{s}}{d x} \Delta x\right)^{2}$ 
Assuming that the net acummulation of energy within the control volume is zero under steady state condition and neglecting higher order terms, the conservation of energy results in the following form:

$P \frac{d u_{a}}{d x}+u_{a} \frac{d P}{d x}+u_{a} f_{a}+u_{s} f_{s}+\rho_{a} \varepsilon_{a} u_{a}^{2} \frac{d u_{a}}{d x}+\rho_{s} \varepsilon_{s} u_{s}^{2} \frac{d u_{s}}{d x}=0$

For the solids-gas flows, the conservation of momentum can be given by the following equation:

$$
\begin{aligned}
& {\left[\left(\rho_{a} \varepsilon_{a} A u_{a}\right)\left(u_{a}+\frac{d u_{a}}{d x} \Delta x\right)-\left(\rho_{a} \varepsilon_{a} A u_{a}\right) u_{a}\right]+\left[\left(\rho_{f l} \varepsilon_{s} A u_{s}\right)\left(u_{s}+\frac{d u_{s}}{d x} \Delta x\right)-\left(\rho_{f l} \varepsilon_{s} A u_{s}\right) u_{s}\right]} \\
& \quad=\left[P A-\left(P+\frac{d P}{d x} \Delta x\right) A\right]-F_{a}-F_{s}
\end{aligned}
$$

Conservation of momentum equation for element volume can be obtained by dividing both sides of equation (7) with elemental volume $(\mathrm{A} \Delta \mathrm{x})$,

$\varepsilon_{a} \rho_{a} u_{a} \frac{d u_{a}}{d x}+\varepsilon_{s} \rho_{f l} u_{s} \frac{d u_{s}}{d x}+\frac{d P}{d x}=-f_{a}-f_{s}$

Conservation of the mass for the gas-phase and solids-phase are represented by the following equations 9 and 10, respectively.

$\frac{d}{d x}\left(\varepsilon_{a} \rho_{a} u_{a}\right)=0$ 
$\frac{d}{d x}\left(\varepsilon_{s} \rho_{f l} u_{s}\right)=0$

Volume fractions for the gas and solid phases obey the relation as following:

$\varepsilon_{a}+\varepsilon_{s}=1$

In equations 4 to 11 , fluidized bulk density has been considered as the representative solids density considering the dune nature of the fluidized dense-phase flow. Equations 12 to 15 , the coupled first order ordinary differential equations have been derived from the system of conservation equations, i.e. equations 6,8 to 10 . Equations 12 to 15 show the evolution of system parameters $u_{s}, u_{a}, \varepsilon_{s}$ and $P$ with respect to the spatial distance $(x)$. Spatial variation of fluidized bulk density, the system parameter $\rho_{f l}$, for the solid phase vanishes as it is a conserved quantity within the system. Thus the evolution equations take the following form:

$\frac{d u_{s}}{d x}=\frac{u_{s}}{\varepsilon_{s}\left(\rho_{f l} u_{s}^{2}\left(u_{s}-u_{a}\right)-\frac{u_{a} P}{\left(1-\varepsilon_{s}\right)}\right)}\left[-\left(u_{s}-u_{a}\right) f_{s}+\frac{u_{a} P}{\rho_{a}} \frac{d \rho_{a}}{d x}\right]$

$\frac{d u_{a}}{d x}=-\frac{u_{a}}{\rho_{a}} \frac{d \rho_{a}}{d x}-\frac{u_{a}}{\left(1-\varepsilon_{s}\right)\left(\rho_{f l} u_{s}^{2}\left(u_{s}-u_{a}\right)-\frac{u_{a} P}{\left(1-\varepsilon_{s}\right)}\right)}\left[-\left(u_{s}-u_{a}\right) f_{s}+\frac{u_{a} P}{\rho_{a}} \frac{d \rho_{a}}{d x}\right]$

$\frac{d \varepsilon_{s}}{d x}=-\frac{1}{\left(\rho_{f l} u_{s}^{2}\left(u_{s}-u_{a}\right)-\frac{u_{a} P}{\left(1-\varepsilon_{s}\right)}\right)}\left[-\left(u_{s}-u_{a}\right) f_{s}+\frac{u_{a} P}{\rho_{a}} \frac{d \rho_{a}}{d x}\right]$

$$
\frac{d P}{d x}=-f_{a}-f_{s}+\left(1-\varepsilon_{s}\right) u_{a}^{2} \frac{d \rho_{a}}{d x}+\frac{\left(\rho_{a} u_{a}^{2}-\rho_{f l} u_{s}^{2}\right)}{\left(\rho_{f l} u_{s}^{2}\left(u_{s}-u_{a}\right)-\frac{u_{a} P}{\left(1-\varepsilon_{S}\right)}\right)}\left[-\left(u_{s}-u_{a}\right) f_{s}+\frac{u_{a} P}{\rho_{a}} \frac{d \rho_{a}}{d x}\right]
$$


The spatial evolution of the system parameters $u_{s}, u_{a}, \varepsilon_{s}$ and $P$, along the length $(x)$ of the pipeline is presented by set of equations 12 to 15 . Several straight segments/sections have been considered for the numerical study of the evolution along the entire length of the pipeline (Figure 1). Large straight sections have been divided into the smaller sections. For the numerical study, section lengths are as follows: 9.1, 20.1, 60.2, 100.3, 144.25, $188.2 \mathrm{~m}$. Coupled ordinary differential equations (equations 12 to 15 ) have been solved numerically in different pipeline sections. Actual air velocity, particle velocity, pressure and solids volume fraction were determined by the numerical solution of the evolution equations using experimental data of $f_{s}$ and $\mathrm{f}_{\mathrm{a}}$. Drag model including gas (fluid) and solid velocities is provided below for completeness (Levy and Mason, 2000).

$F_{d 1}=\frac{3 r_{s 1} A_{1}}{4 D_{P}} C_{d 1} \rho_{g 1}\left(U_{g 1}-U_{s 1}\right)\left|U_{g 1}-U_{s 1}\right|$

$F_{d 2}=\frac{3 r_{s 2} A_{2}}{4 D_{P}} C_{d 2} \rho_{g 2}\left(U_{g 2}-U_{s 2}\right)\left|U_{g 2}-U_{s 2}\right|$

These differential equations have been solved as an intial value problem, where the corresponding intial values for the parameters $u_{s}, u_{a}, \varepsilon_{s}$ and $P$ have been acquired from the experimental data. In a particular section of the pipeline, the following parameters $f_{s}, f_{a}, \rho_{a}$ and $\frac{d \rho_{a}}{d x}$ have been taken from the experimental data of fly ash conveyed through $254 \mathrm{~m}$ long test rig. For obtaining the initial value of $u_{s}$, the following relationship has been used. It has been considered that when the fly ash is fed into the pipeline from the blow tank, the aerated mixture 
occupies the full cross section of the pipe. The extent of occupancy subsequently decreases along the direction of flow.

$u_{s}=\frac{m_{s}}{A \rho_{f l}}$

Numerically determined values obtained at the end of the first pipe section are used as the initial conditions for the successive section. This method has been followed in all subsequent pipe sections till the exit point of the pipeline. Thus, values of the parameters $u_{s}, u_{a}, \varepsilon_{s}, u_{s} / u_{a}$ and $P$ have been determined for the final point of each section, corresponding to $x=9.1,20.1,60.2$, $100.3,100.3,144.3$ and $188.2 \mathrm{~m}$ ) were obtained. The variation of $u_{s}, u_{a}, u_{s} / u_{a}$ and $\varepsilon_{s}$ along the length of pipe from $x=9.1$ to $188.2 \mathrm{~m}$ ) are provided in Figures 6 to 9. The results correspond to solids mass flow rate of 18, 14 and $10 \mathrm{t} / \mathrm{h}$ and two different air mass flow rates of 0.06 and 0.16 $\mathrm{kg} / \mathrm{s}$ and for the fluidized bulk density of $330 \mathrm{~kg} / \mathrm{m}^{3}$.

Figure 6

Figure 7

Figure 8

Figure 9 
Figure 6 shows that for all cases, there is an overall increase in the values of particle velocities in the direction of flow. Higher gas flow rates and solids flow rates have resulted in larger values of particle velocities. For both the air flows and all three different solids flow rates, the rates of increment in particle velocity increases with an increase in distance from the blow tank, with a sharper rate of rise for the $0.16 \mathrm{~kg} / \mathrm{s}$ of air flow compared to $0.06 \mathrm{~kg} / \mathrm{s}$. Figure 7 shows that for all cases, there is an overall increase in the values of actual gas velocities along the direction of flow. For low air flow $(0.06 \mathrm{~kg} / \mathrm{s})$, the actual gas velocities for higher material flow rate $(18 \mathrm{t} / \mathrm{h})$ are clearly higher compared to the lower tonnages (14 and $10 \mathrm{t} / \mathrm{h}$ ). This is due to the higher solids volume occupancy in pipeline, resulting in reduced area available for gas flows. For higher air flows $(0.16 \mathrm{~kg} / \mathrm{s})$, the actual gas velocities are expectedly higher compared to $0.06 \mathrm{~kg} / \mathrm{s}$ of air flow). In the present work, it has been considered that just at the point of feeding the powders into the pipeline (i.e. at the point of blow tank discharge), powders are pushed full bore and the feed velocities of powders are not affected by the conveying air velocities. As evident from Figure 6, as the flow progresses, the powder velocities are different for different air velocities. This is because with higher air flow rates, the powders are dragged or sheared more into the air stream and also the powders get more free space to accelerate. Fluidized bulk density curve (Figure 4) indicates the decrease in fluidized bulk density with an increase in air flow rate. The considerations made in the present study are just a starting point for this new line of research and that the further work is needed to verify relevant parameters during the actual flow conditions of fine powders. It can be seen from Figure 8 that the values of the ratio of particle to gas velocities increase in the direction of flow for all cases, indicating that the rate of rise in particle velocity is more dominating compared to the corresponding rise in gas velocity (due to gas expansion). 
There is a greater slip beween the gas and solids phases in the direction of flow. It can be observed from Figure 8 that there is a sharp rise in the value of the solids to gas velocity ratio towards the end of the pipeline, especially for the higher air flow rates $(0.16 \mathrm{~kg} / \mathrm{s})$. Solids volumetric concentration is expectedly higher for higher solids flow rates and the same decreases along the direction of flow (Figure 9) for all tonnages and air flow rates. Although, there have been a considerable amount of research carried out in recent years to experimentally measure and develop empirical models for the coarser particles being transported in dilute-phase, very few efforts have been directed towards particle velocity measurements for fine powders, especially under the dense-phase flow conditions. A comprehensive list of such models are provided by Wei et al.(2011). Wei et al. (2011) reported that the model of Klinzing et al. is applicable in the particle size range of 67 to $900 \mu \mathrm{m}$. The Hong and Shen model has been reported (Wei et al., 2011) to be applicable for "High solid-gas ratio, fine powder". The emprical models of Klinzing et al. and Hong and Shen are provided by equations 19 and 20, respectively.

$$
\begin{aligned}
& \mathrm{u}_{\mathrm{s}}=\left(\mathrm{u}_{\mathrm{a}}-\mathrm{w}_{\mathrm{fo}}{ }^{0.71}\right) D^{0.019} \\
& \mathrm{u}_{\mathrm{s}}=\mathrm{u}_{\mathrm{a}}\left[1-0.533\left(\frac{1000 \rho_{\mathrm{a}}}{\rho_{\mathrm{s}}}\right)^{1.093}\left(\frac{\mathrm{D}}{100 \mathrm{~d}_{\mathrm{p}}}\right)^{-0.721}\right]
\end{aligned}
$$

It has been considered in the present work that as the Klinzing et al. and Hong and Shen models are reportedly (Wei et al., 2011) applicable in the fine powder range or atleast close to its range, hence these two empirical models are to used to predict particle or dune velocity that are compared with the numerical results provided in Figure 6. The results of comparison are provided in Figure 10 (for high and low solids loading ratio). Wei et al. (2011) used a term ' $U_{g}$ ' 
in place of ' $u_{a}$ ' and mentioned ' $U_{g}$ ' as the "superficial gas velocity", hence the same ("superficial gas velocity") has been used in Figure 10. Fluidized bulk density has been used in equation (20).

\section{Figure 10}

It can be seen from Figure 10 that the particle velocity values obtained using the numerical model better match with the empirical model of Hong and Shen model. Using the numerical results obtained for the ratio of particle to actual air velocity $\left(u_{s} / u_{a}\right)$ (as provided in Figure 8 ) for 18,14 and $10 \mathrm{t} / \mathrm{h}$ of solids slow rates and for 0.06 and $0.16 \mathrm{~kg} / \mathrm{s}$ of gas flow rates, a power function based relation for particle to actual gas velocity has been determined using multiple regression method, as given by equation 21 . This relation has been used further to model solids friction factor. The high value of $R^{2}$ (absolute value of 0.97 ) indicates good fit.

$\frac{u_{s}}{u_{a}}=10^{-2.026} m^{* 0.912}\left(\frac{w_{f o}}{V}\right)^{-0.135}$

\section{Developing model for solids friction factor and scale-up validation}

For modeling solids friction factor for the dense-phase flow of fine powders, a well-known and reliable dilute-phase model ("Weber-A4" model, Wypych et al., 1990) has been considered as the starting point. This model has been reported to deliver accurate predictions for dilute-phase flow 
under different scale-up conditions (Wypych et al., 1990). The Weber-A4 model considers that the solids friction factor comprises of two factors: energy loss due to impact and friction between particle-particle/air/pipe wall and that due to keeping the particles in suspension. The "Weber-A4" model is given by equation (22).

$\lambda_{s}=\lambda_{s}{ }^{*} \frac{C}{V}+\frac{2 \frac{w_{f o}}{V}}{\frac{C}{V} F r^{2}}$

In the above expression, $\lambda_{s}{ }^{*}$ is considered to have a constant value and represents the impact and friction component corresponding to dilute-phase condition. For fine powders and dilute-phase flows, the C/V value is typically assumed to be approaching unity (Wypych et al., 1990 and Setia et al., 2016). This seems to be a reliable assumption for very dilute phase flows. However, the same cannot be assumed for dense-phase flows (as evident from Figure 8). Using the experimental steady state pressure drop data obtained from P2-P3 straight pipeline section and using $\frac{C}{V}=\frac{u_{s}}{u_{a}}$ values obtained from equation (21) for a range of test conditions (combinations of air and solids flow rates), different values of $\lambda_{s}{ }^{*}$ have been determined. Subsequently a model for $\lambda_{s}{ }^{*}$ has been generated using Volumetric Loading Ratio (VLR) and dimensionless velocity terms. VLR is represented as:

$V L R=\left\{\left(m_{s} / \rho_{s}\right) /\left(m_{a} / \rho_{a}\right)\right\}$

Rautiainen et al. (1999) and Behera et al. (2013) have used solids volume fraction to model pneumatic transport. Rautiainen et al. (1999) mentioned that solids volume fraction will affect 
the slip velocity of particles and clustering. The gas has to travel through the tortuous path available between clusters of solid particles. This tortuous path would contribute to its energy drop of the gas-phase. Bosse et al. (2006) proposed that "one-way coupling" is applicable for dilute-phase and "two-way coupling" is more relevant for dense-phase flow situations. Similar conclusions were made by Ahmed and Elgobashi (2000), who proposed that the change of vorticity dynamics contributes to change in turbulence energy production rate of the carrier fluid. It was suggested by Huber and Sommerfield (1998) that the finer particles would get trapped in eddies and hence, they would have the similar velocities as the gas phase. From above it appears that volumetric concentration of solids will have significant influence on turbulence pattern of the gas-phase. Therefore, solids volume concentration has been used to model solids friction factor in the present paper. Recent investigations of Setia et al. $(2015,2016)$ have shown that Volumetric Loading Ratio (VLR) and dimensionless velocity $w_{f o} / V$ terms represent the densephase flow conditions much better than the solids loading ratio and Froude number. Using these dimensionless groupings, the following model for $\lambda_{s}{ }^{*}$ has been developed using steady state P2P3 pressure tapping data. The high value of $R^{2}$ (absolute value of 0.94) indicates good fit.

$\lambda_{\mathrm{s}}^{*}=10^{-0.0427} V L R^{-1.137}\left(\frac{w_{f o}}{V}\right)^{1.298}$

$\lambda_{s}^{*}$ and $\frac{C}{V}$ or $\frac{u_{s}}{u_{a}}$ are to be obtained using the models given by equations (24) and (21), respectively, and the same were then used in equation (22) to determine the values of $\lambda_{s}{ }^{*}$. The newly develop model for solids friction factor has been validated for scale-up accuracy by predicting pressure drop in longer and larger diameter pipelines (65 mm I.D. $\times 254 \mathrm{~m}$ long and80/100 mm I.D. $\times 407$ m long) for different solids and air flow rates by comparing the predicted versus experimental 
pneumatic conveying characteristics. An iterative program (using SOLVER and MACRO in Microsoft Excel 2007) has been developed to estimate the total pipeline pressure drop by segmenting the entire pipeline into several smaller straight pipe sections and bends. The program starts from the exit point of the pipe and progressively calculates pressure drops in different pipe sections up to the blow tank. Chambers and Marcus (1986) models have been used to calculate the pressure drops due to initial acceleration, verticals and bends. These are provided by equations 25 to 27. The results are provided in Figures 11 and 12.

Acceleration loss $\quad: \quad \Delta P_{\text {accel }}=\rho_{a} V^{2}\left(1+2 m^{*} C / V\right) / 2$

Vertical loss $\quad: \quad \Delta P_{V}=m^{*} \rho_{a} g L_{V} V / C$

Bend loss $\quad: \quad \Delta P_{b}=N B\left(1+m^{*}\right) \rho_{a} V^{2} / 2$

Predictions using a recent two-layer based model (developed by one of the author) have been superimposed on Figures 11 and 12 to evaluate the relative accuracy of the newly developed model. The two-layer model of Setia et al (2016) is provided below by equation (28). The value of $\lambda_{\mathrm{s}}{ }^{*}$ was taken as 0.0074 for the two layer model of Setia et al. (2016).

$\lambda_{s}=\tau_{1}\left(23.54(V L R)^{-0.61}\left(w_{f o} / V\right)^{1.71}\right)+\tau_{2}\left(\lambda_{s}^{*} C / V+2 \beta_{0} /\left[(C / V) F r^{2}\right]\right)$

\section{Figure 11}




\section{Figure 12}

It can be seen in Figure 11 that the two layer model of Setia et al. (2016) provided slight underprediction in the dense-phase or low velocity zone, although it predicted very well in the dilutephase. The newly developed model provided accurate prediction in the low velocity (densephase) zone, though it provides slight over-prediction in the high velocity range. For the 80/100 mm I.D. x $407 \mathrm{~m}$ long pipe pipeline (Figure 12), both the new and Setia et al. (2016) models provide similar over-predictions at both dense and dilute-phase conditions. Overall, it can be concluded that the new model and the Setia et al. (2016) model provided similar accuracy under similar scale-up conditions, with the new model providing some improvements in dense-phase region. It has been shown in previously (Setia et al., 2016) that the two-layer model of Setia et al. (2016) provided better reliable predictions compared to the other existing models (that are in the format of equation 2 and 3). This signifies that it is important to use particle and actual gas velocity terms in the model of solids friction factor. The two layer model, developed by some of the authors of the present study, compares well with the predictions obtained by the new developed model for the $407 \mathrm{~m}$ long pipe. However, in the $254 \mathrm{~m}$ long pipe, for both the ash flow rates, the two-layer model provides slight under-prediction in the low velocity range. The main prospect of the new model is that it is an amended form of the WEBER A4 model (modified to suit WEBER A4 model in dense-phase) by using a particle to actual air velocity ratio term (which otherwise is typically considered to be having the value of unity or close to it). WEBER A4 model is known to be a reliable model for dilute-phase under scale-up condition. Therefore, the new model (basing based on WEBER A4 model) is expected to predict accurately under wide range of scale-up conditions. The other novelty of the new model is it uses the 
important particle velocity term, which has been ignored in the two-layer model. Therefore, the new model fundamentally addresses the flow situation better. Future work would include further validation of this new modelling technique to different other scale-up pipelines and products.

\section{Conclusion}

Numerical modelling has been carried out to solve the governing equations of flow for fluidized dense-phase pneumatic transport of fly ash for different air and solids flow rates. The results have shown that the particle and actual gas velocities and the ratio of the two velocities increase in the direction of flow, while a reverse trend was found for the solids volumtric concentration. An existing model for solids friction factor, which is known to be reliable for pure dilute-phase, has been amended to make it suitable for dense-phase flow conditions by representing particle to gas velocity in terms of solids loading ratio and dimensionless velocity and impact and solids friction factor by volumtric loading ratio and dimensionless velocity. The newly developed model for solids friction factor, when tested for scale-up accuracy by using it to predict the total pipeline pressure drops for larger and longer pipes and by comparing the experimental and predicted conveying characteristics, has resulted in accuracy of predictions that is similar to a recently developed two-layer based model. The results indicate the importance of using particle and actual gas velocity terms in modeling solids friction factor. Future work should be carried out to develop reliable experimental techniques for the reliable measurement of particle velocity 
of fine powders under fluidized dense-phase flow condition. Future research should also include developing accurate solids friction factor model for stepped diameter pipelines.

\section{Acknowledgement}

Baldeep Kaur would like to acknowledge the financial support of UGC through UGC-BSR Research Fellowships in Sciences [F.4-1/2006(BSR)/7-304/2010(BSR)]. The authors would also

like to thank Mr. Gautam Setia, Mr. Amanpreet Chawla and Ms. Kathi Tejashwi of Thapar University for the experimental work.

\section{List of symbols and abbreviations}

A

$A_{1}, A_{2}$

$a, b, c$

$B$

C

$C_{d k}$
Cross sectional area of control volume $\left[\mathrm{m}^{2}\right]$

Area of the cross-section occupied by the dense and the dilute phase layers, respectively $\left[\mathrm{m}^{2}\right]$

Exponents of power function

Bend loss factor

Particle velocity $[\mathrm{m} / \mathrm{s}]$

Drag coefficient for particle in layer $k$ 


\begin{tabular}{|c|c|}
\hline$D$ & Internal diameter of pipe $[\mathrm{m}]$ \\
\hline$D_{P}$ & Mean particle diameter $[\mu \mathrm{m}]$ \\
\hline$d_{p}$ & Particle diameter $[\mu \mathrm{m}]$ \\
\hline$d_{50}$ & Median particle diameter $[\mu \mathrm{m}]$ \\
\hline$F_{d k}$ & Body force between the particles in layer $k[\mathrm{~N}]$ \\
\hline$F r=V /(g D)^{0.5}$ & Froude number of flow \\
\hline$F r_{i}=V_{i} /(g D)^{0.5}$ & Froude number of flow at the beginning of pipe (initial Froude number) \\
\hline$F r_{s}=w_{f o} / \sqrt{g d_{50}}$ & Particle Froude number \\
\hline$F_{a}$ & Frictional force due to air phase on pipe wall $[\mathrm{N}]$ \\
\hline$F_{s}$ & Frictional force due to solids phase on pipe wall $[\mathrm{N}]$ \\
\hline$f_{a}$ & Frictional force per unit volume due to air phase $\left[\mathrm{N} / \mathrm{m}^{3}\right]$ \\
\hline$f_{s}$ & Frictional force per unit volume due to solids phase $\left[\mathrm{N} / \mathrm{m}^{3}\right]$ \\
\hline$g$ & Acceleration due to gravity $\left[\mathrm{m} / \mathrm{s}^{2}\right]$ \\
\hline K & Constant of power function \\
\hline$L$ & Length of horizontal pipe or test section $[\mathrm{m}]$ \\
\hline$L_{v}$ & Length of vertical pipe or test section $[\mathrm{m}]$ \\
\hline$m_{f}, m_{a}$ & Mass flow rate of air $[\mathrm{kg} / \mathrm{s}]$ \\
\hline$m_{s}$ & Mass flow rate of solids $[\mathrm{kg} / \mathrm{s}]$ \\
\hline$m^{*}=m_{s} / m_{a}$ & Solids loading ratio \\
\hline$N$ & Number of bends \\
\hline$P$ & Pressure $[\mathrm{Pa}]$ \\
\hline$\Delta P$ & Pressure drop through a straight horizontal pipe or pipe section $[\mathrm{Pa}]$ \\
\hline
\end{tabular}


$\Delta P_{\text {accel }}$

$\Delta P_{b}$

$\Delta P_{V}$

$r_{s k}$

$u_{a}$

$u_{s}$

$V, \mathrm{U}_{\mathrm{g}}$

$U_{g k}$

$U_{s k}$

$V_{a}=m_{a} / \rho_{a}$

$V_{s}=m_{s} / \rho_{f l}$

$V L R=\left\{\left(m_{s} / \rho_{s}\right) /\left(m_{f} / \rho_{a}\right)\right\}$

$w_{\text {fo }}$

$w_{f o} / V$

$x$

$\rho, \rho_{a}$

$\rho_{g k}$

$\rho_{S}$

$\rho_{b}$

$\rho_{f l}$

$\lambda_{f}$

$\lambda_{s}$
Pressure drop due to initial acceleration $[\mathrm{Pa}]$

Pressure drop due to the bends $[\mathrm{Pa}]$

Pressure drop due to the verticals $[\mathrm{Pa}]$

Volume fraction of the solids phase in layer $k$

Actual gas velocity $[\mathrm{m} / \mathrm{s}]$

Particle or dune velocity $[\mathrm{m} / \mathrm{s}]$

Superficial air or gas velocity $[\mathrm{m} / \mathrm{s}]$

Velocity of gas phase in layer $k[\mathrm{~m} / \mathrm{s}]$

Velocity of solids phase in layer $k[\mathrm{~m} / \mathrm{s}]$

Volumetric flow rate of air $\left[\mathrm{m}^{3} / \mathrm{s}\right]$

Volumetric flow rate of solids $\left[\mathrm{m}^{3} / \mathrm{s}\right]$

Volumetric loading ratio

Free settling velocity of an isolated particle $[\mathrm{m} / \mathrm{s}]$

Dimensionless velocity

Horizontal distance in the direction of flow starting at blow tank [m]

Density of air $\left[\mathrm{kg} / \mathrm{m}^{3}\right]$

Density of gas phase in layer $k\left[\mathrm{~kg} / \mathrm{m}^{3}\right]$

Particle density $\left[\mathrm{kg} / \mathrm{m}^{3}\right]$

Loose-poured bulk density $\left[\mathrm{kg} / \mathrm{m}^{3}\right]$

Fluidized bulk density $\left[\mathrm{kg} / \mathrm{m}^{3}\right]$

Air/gas only friction factor

Solids friction factor through straight pipe 


$\begin{array}{ll}\lambda_{s}^{*} & \text { Impact and friction factor for solids } \\ \varepsilon_{a}=V_{a} /\left(V_{a}+V_{s}\right) & \text { Volume fraction of air } \\ \varepsilon_{s}=V_{s} /\left(V_{a}+V_{s}\right) & \text { Volume fraction of solids }\end{array}$

\section{References}

Ahmed, A.M. and Elghobashi, S. (2000). On the mechanisms of modifying the structure of turbulent homogeneous shear flows by dispersed particles. Physics of Fluids, 12, 29062920.

Barth, W. (1958). Strömungsvorgänge beim Transport von Festteilchen und Flüssigkeitsteilchen in Gasen. Chemie - Ing. - Techn, 30, 171-180.

Behera, N., Agarwal, V.K., Jones, M.G., and Williams, K.C. (2013). Modeling and analysis for fluidized dense phase conveying including particle size distribution. Powder Technology, $235,386-394$.

Bosse, T., Kleiser, L. and Meiburg, E. (2006). Small particles in homogeneous turbulence. Physics of Fluids, 18, 1-17.

Chambers, A.J. and Marcus, R.D. Pneumatic conveying calculations. In the proceedings of $2^{\text {nd }}$ International Conference on Bulk Materials Storage and Transportation, Wollongong, Australia, 7-9 July, 2006, pp. 49-52.

Huber, N. and Sommerfeld, M. (1998). Modelling and numerical calculation of dilute-phase pneumatic conveying in pipe systems. Powder Technology, 99, 90-101.

Jones, M.G. and Williams, K.C. (2003). Solids friction factors for fluidized dense-phase conveying, Particulate Science and Technology, 21, 45-56. 
Levy, A. and Mason, D.J. (2000). Two-layer model for non-suspension gas-solids flow in pipes, Powder Technology, 112, 256-262.

Mallick, S.S., PhD Dissertation (2009). Modelling fluidised dense phase pneumatic conveying of powders, University of Wollongong.

Marcus, R.D., Leung, L.S, Klinzing, G.E. and Rizk, F. (1990). Pneumatic conveying of solids A theoretical and practical approach. Publ. Chapman and Hall.

Pan, R. and Wypych, P. W. Dilute and dense phase pneumatic conveying of fly ash, In Proceedings of the $6^{\text {th }}$ International Conference on Bulk Materials Storage and Transportation. Wollongong, NSW, Australia, 28-30 September, 1998. pp. 183 - 189.

Pan, R. (1999). Material properties and flow modes in pneumatic conveying. Powder Technology, 104, 157-163.

Ratnayake, C. and Datta, B.K. (2007). A Unified scaling-up technique for pneumatic conveying systems. Particulate Science and Technology, 25, 289-302.

Setia, G. and Mallick, S.S. (2015). Modelling fluidized dense-phase pneumatic conveying of fly ash, Powder Technology, 270, 39-45.

Setia, G., Mallick, S.S., Wypych, P.W. and Pan, R. (2016). Modeling solids friction factor for fluidized dense-phase pneumatic transport of powders using two layer flow theory, Powder Technology, 294, 80-92.

Weber, M. (1981). Principles of hydraulic and pneumatic conveying in pipes, Bulk Solids Handling, 1, 57-63.

Wei, W., Qingliang, G., Yuxin, W., Hairui, Y., Jiansheng, Z and Junfu, L. (2011). Experimental study on the solid velocity in horizontal dilute phase pneumatic conveying of fine powder, Powder Technology, 212, 403-409. 
Wypych, P.W., Kennedy, O.C., and Arnold, P.C. (1990). The future potential of pneumatically conveying coal through pipelines, Bulk Solids Handling, 10, 421-427. 


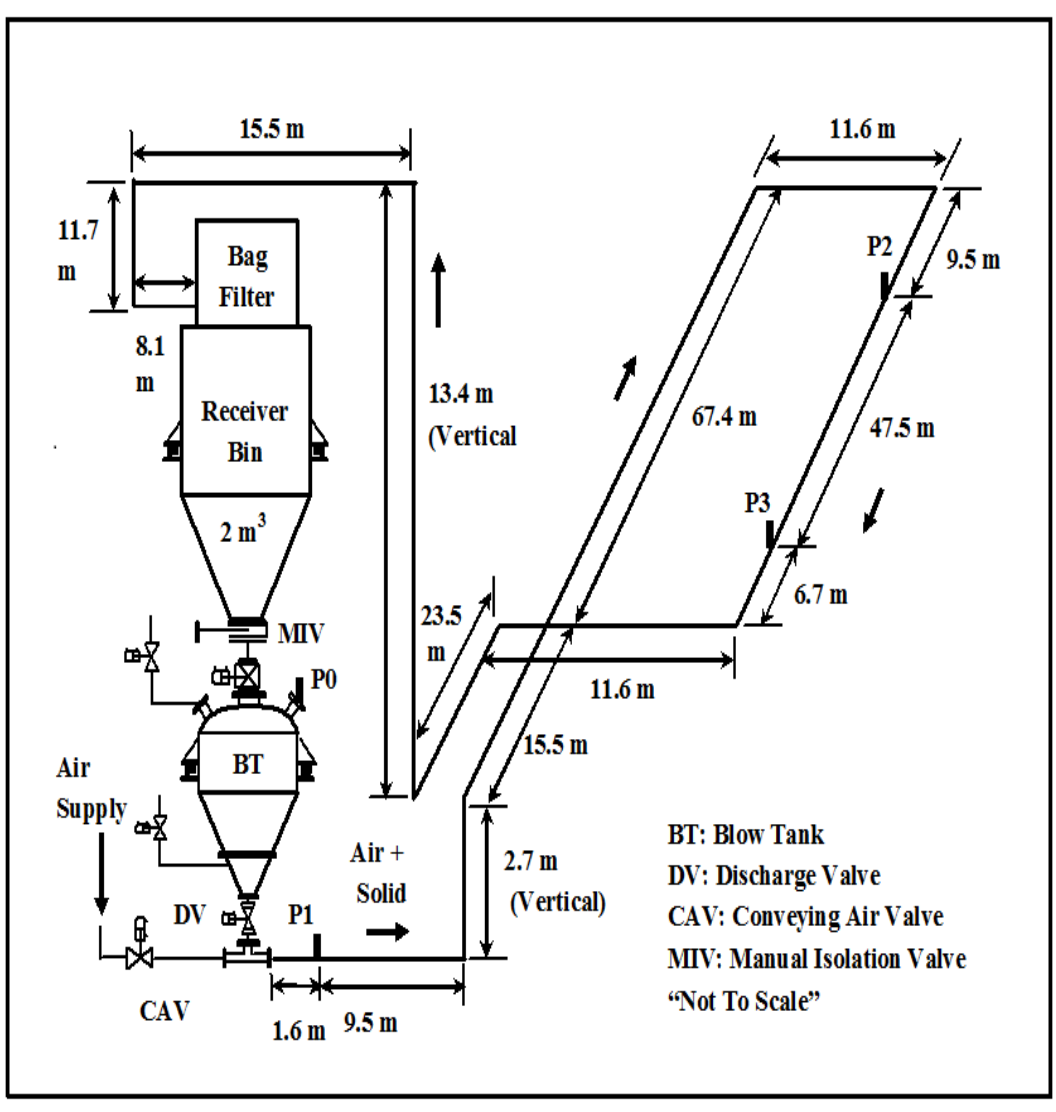

Figure 1(a): 65 mm I.D. $\times 254$ m long pipeline

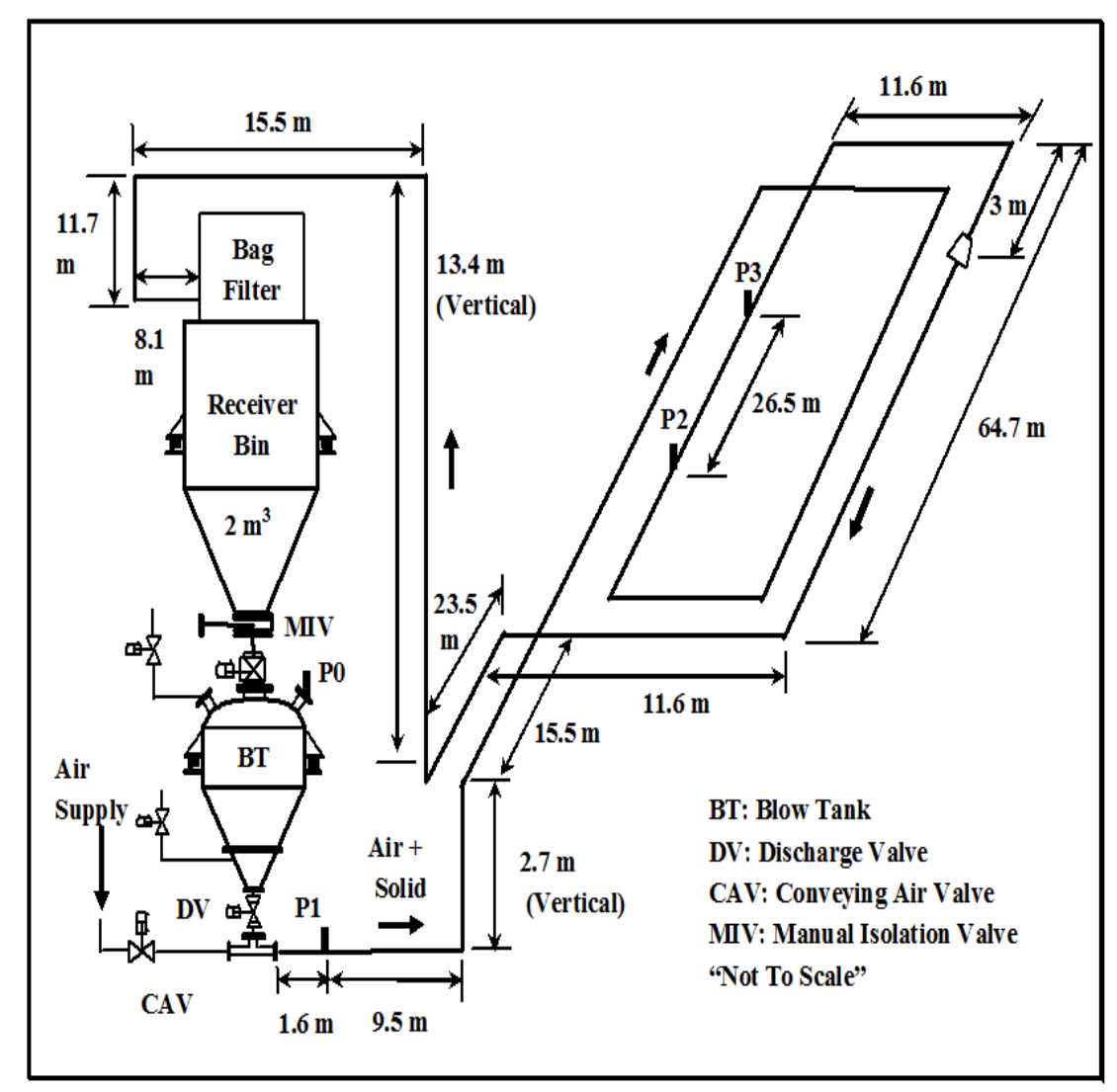

Figure 1(b): 80 and 100 mm I.D. $\times 407$ m stepped-diameter pipeline

Figure 1. Schematic diagram of test rig at Fujian Longking Co Ltd. 
Figure 2

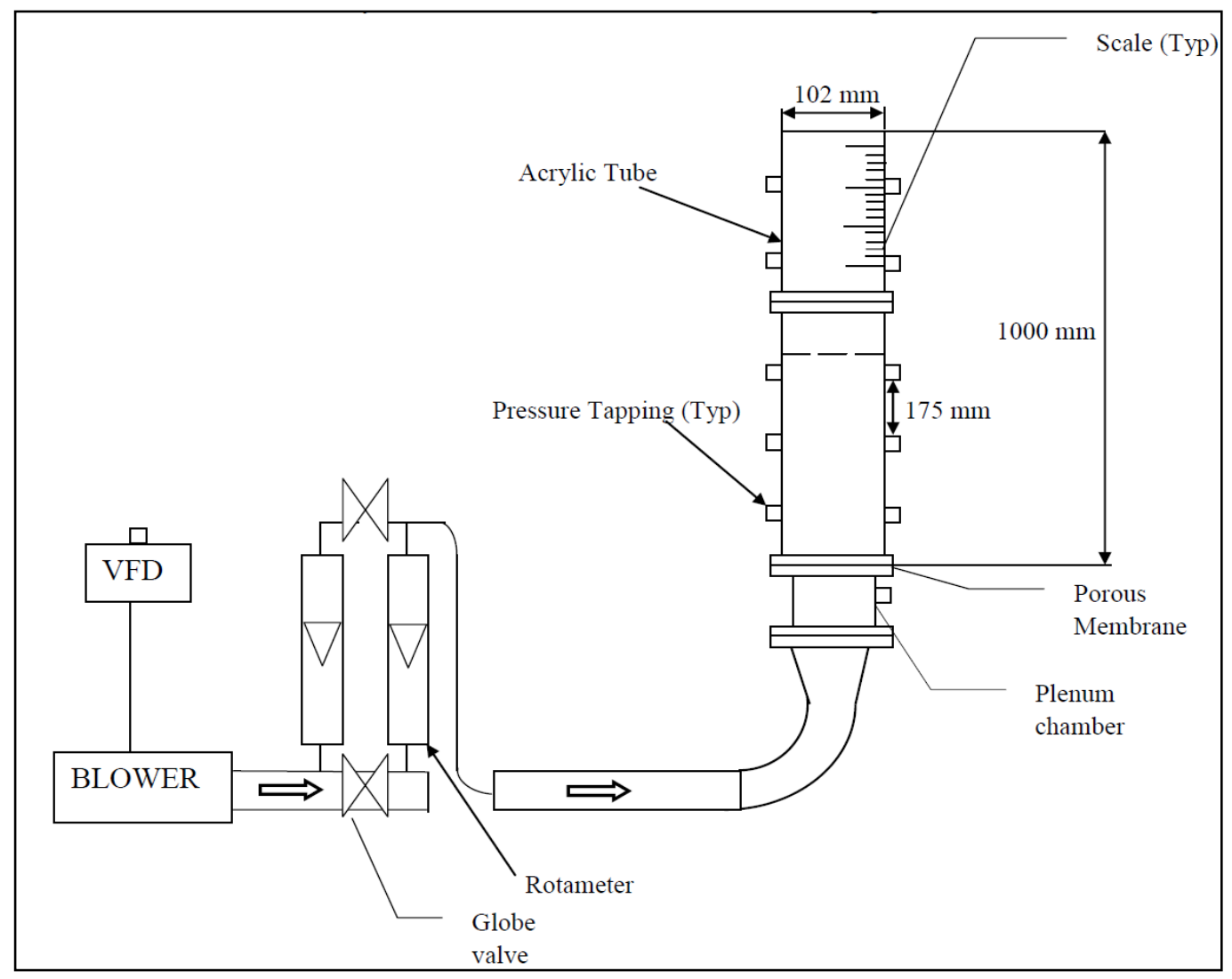

Figure 2: Fluidization and de-aeration chamber 
Figure 3

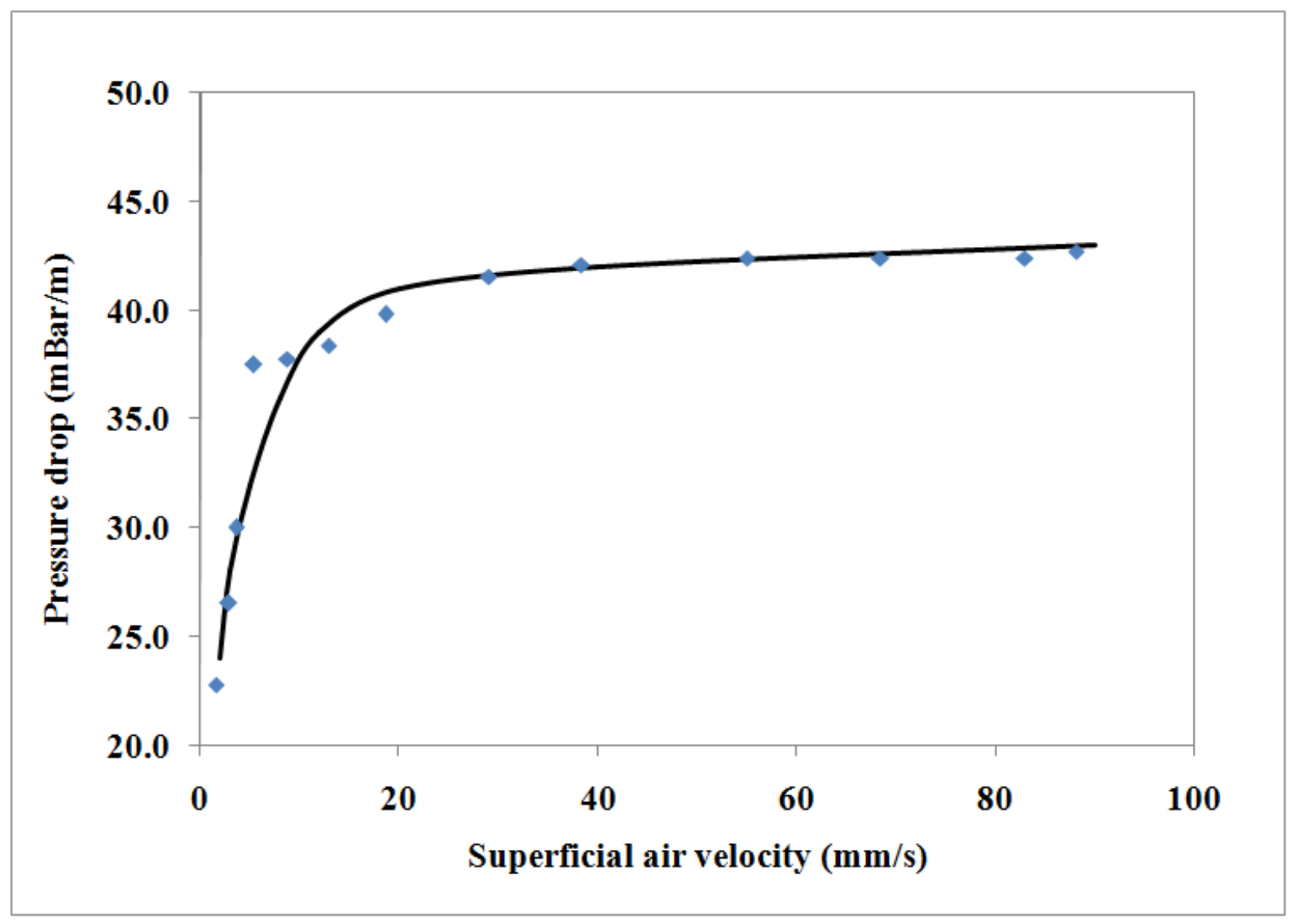

Figure 3: Fluidization curve for the fly ash sample (fly ash conveyed). 
Figure 4

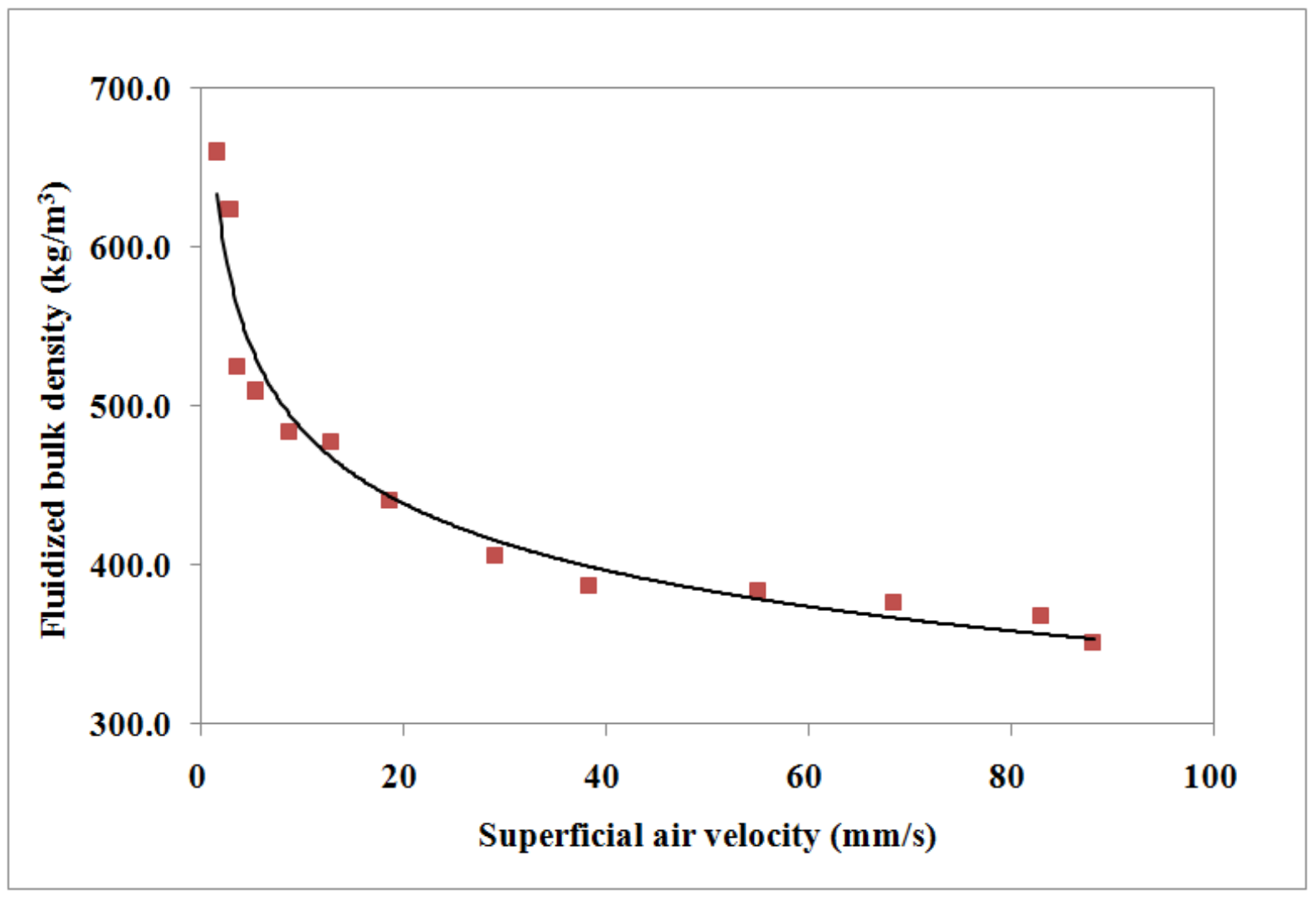

Figure 4: Fluidized bulk density curve for the fly ash sample (fly ash conveyed) 


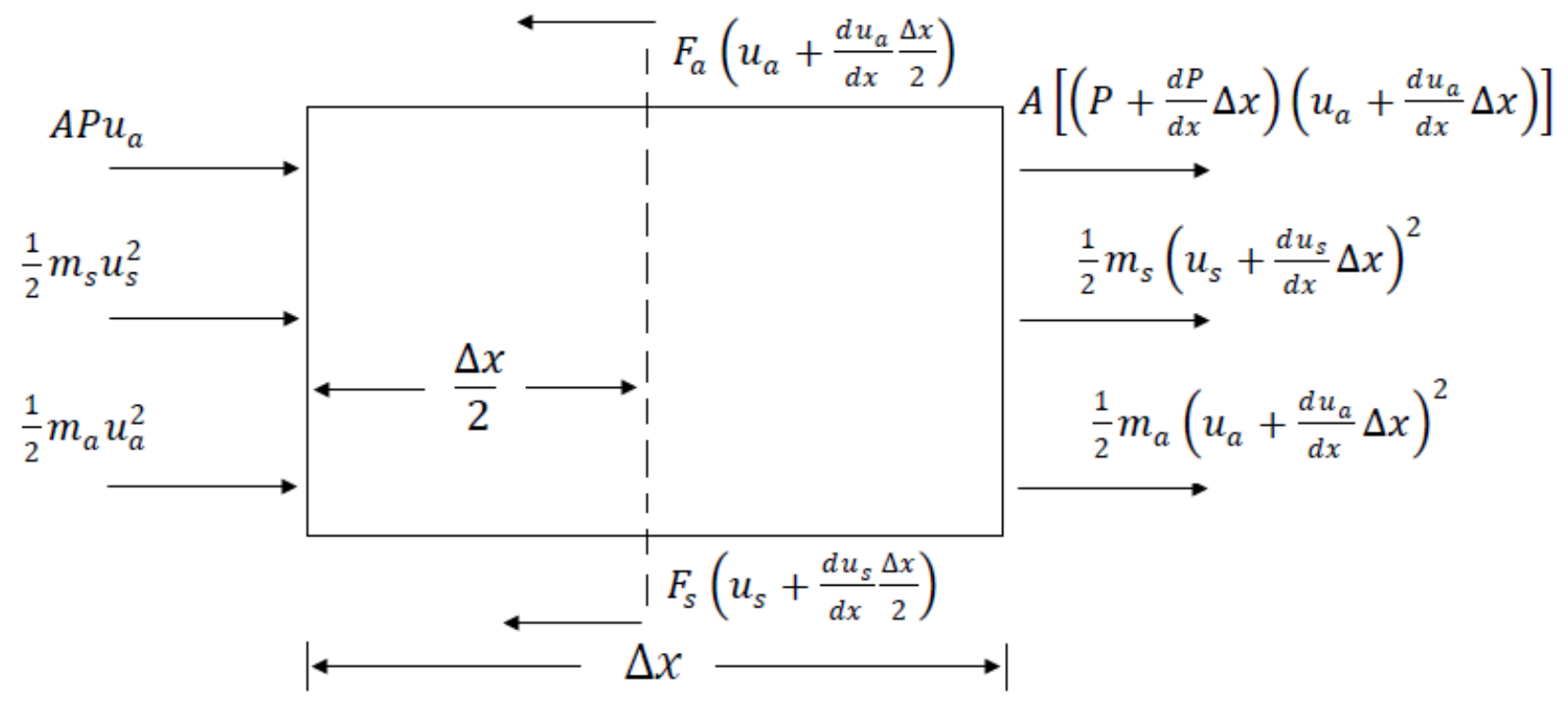

Figure 5: Energy interactions across a control volume. 


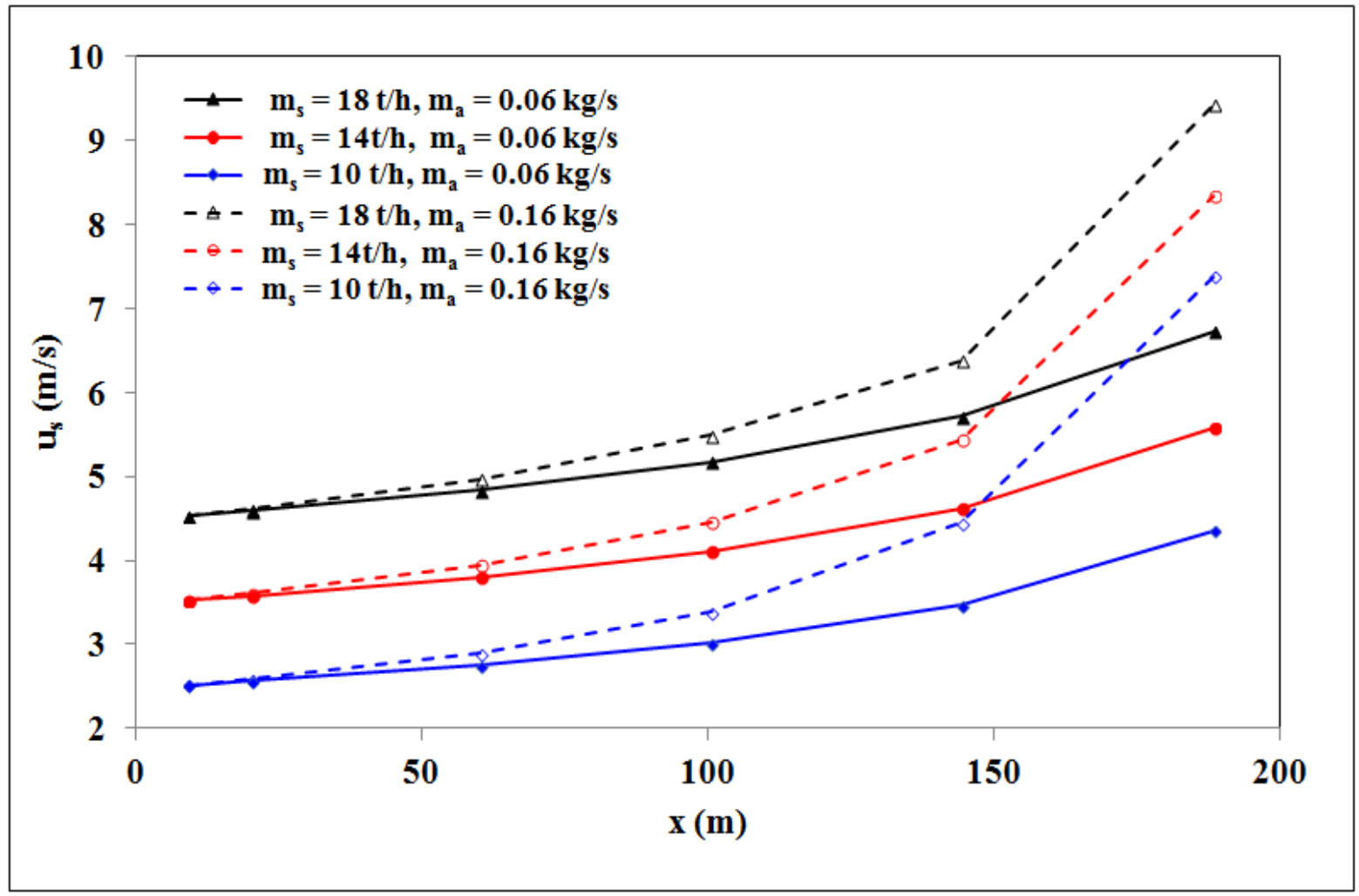

Figure 6: Variation of dune velocity with respect to the spatial distance $(x)$ along the flow direction for different air flow rates $(0.06$ and $0.16 \mathrm{~kg} / \mathrm{s})$ and solids mass flow rates $(18,14$ and $10 \mathrm{t} / \mathrm{h})$ 


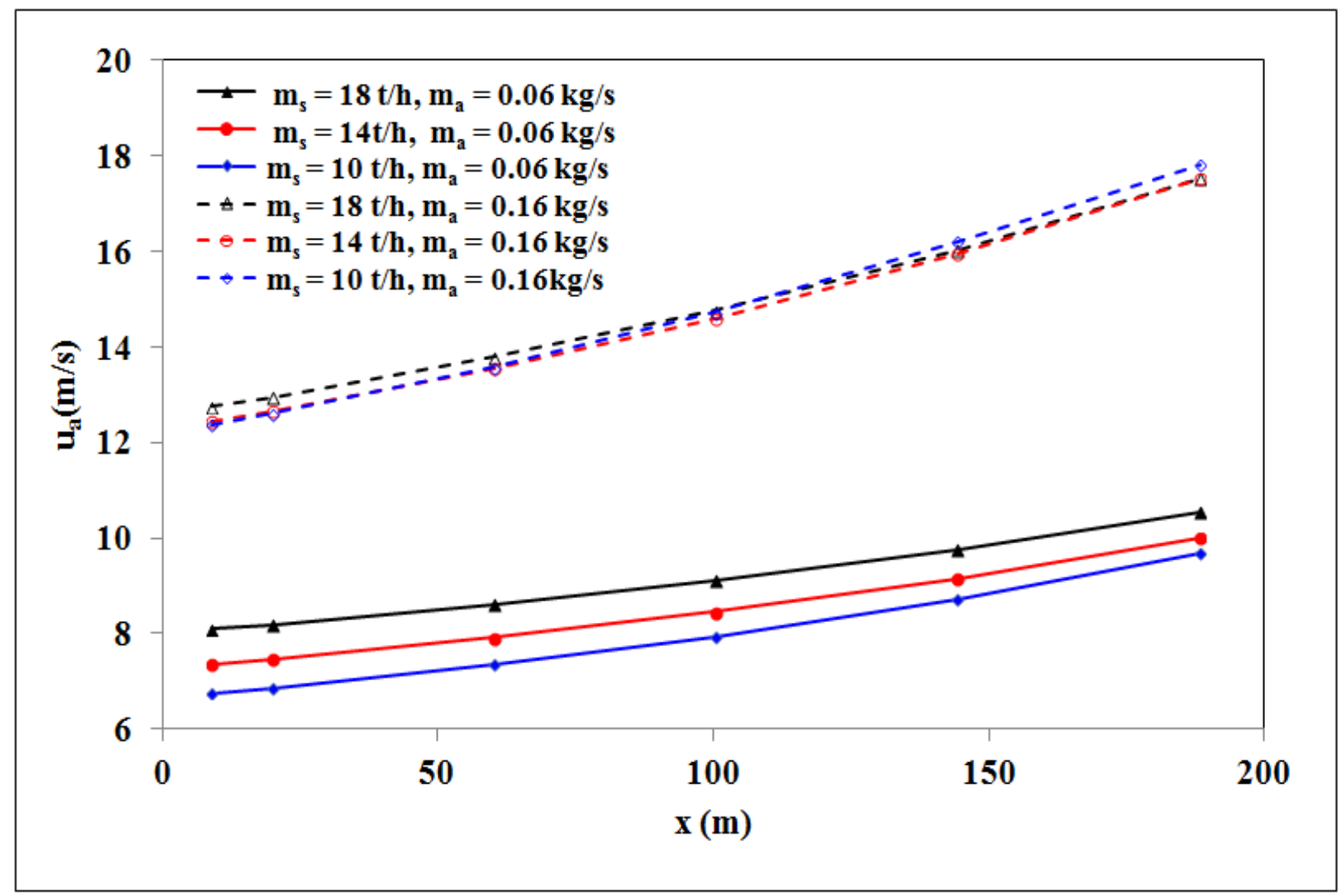

Figure 7: Variation of actual air velocity with respect to the spatial distance $(x)$ along the flow direction for different air flow rates $(0.06$ and $0.16 \mathrm{~kg} / \mathrm{s})$ and solids mass flow rates $(18,14$ and $10 \mathrm{t} / \mathrm{h}$ ) 


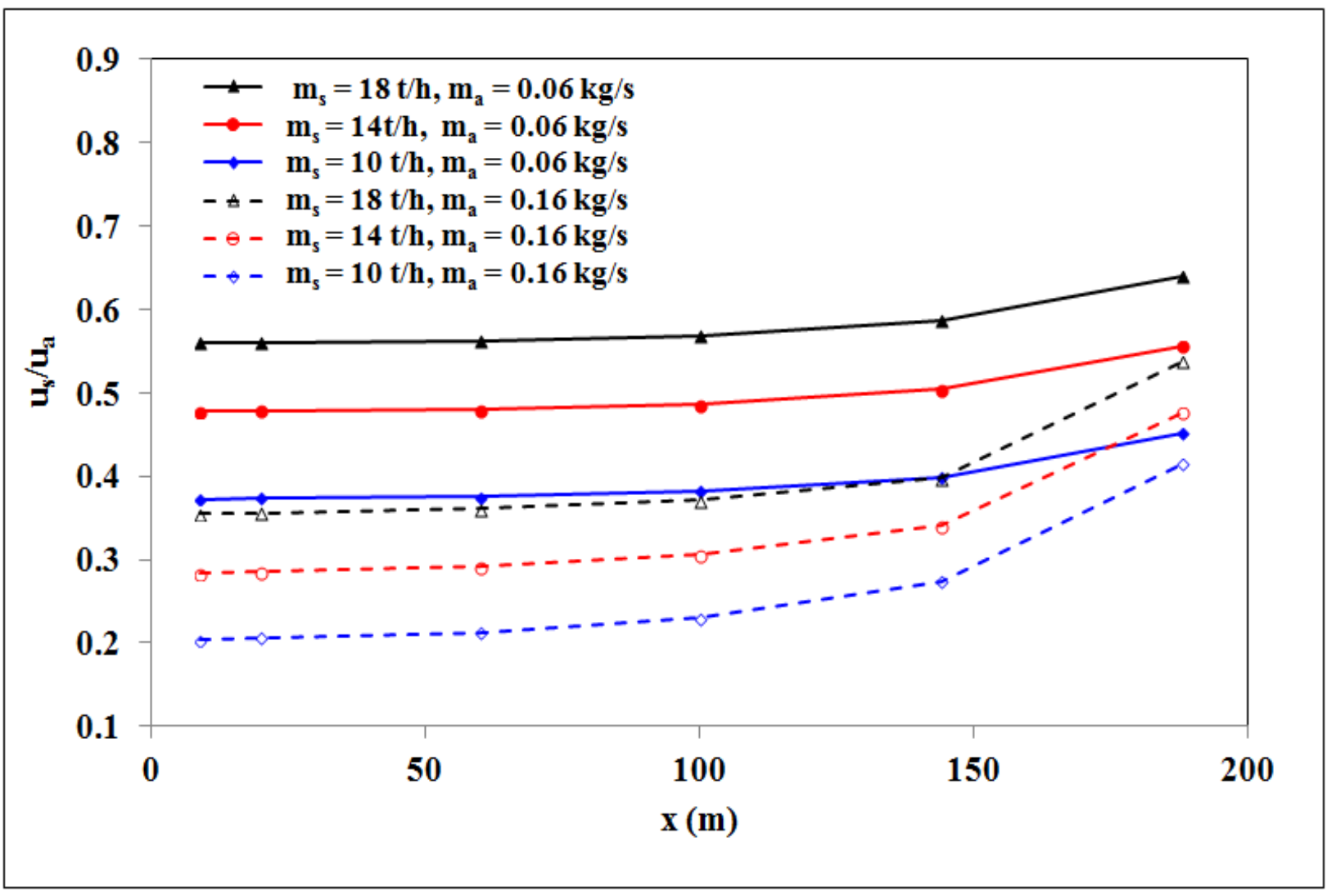

Figure 8: Variation of ratio of dune to actual air velocity with respect to the spatial distance $(x)$ along the flow direction for different air flow rates $(0.06$ and $0.16 \mathrm{~kg} / \mathrm{s})$ and solids mass flow rates $(18,14$ and $10 \mathrm{t} / \mathrm{h})$ 


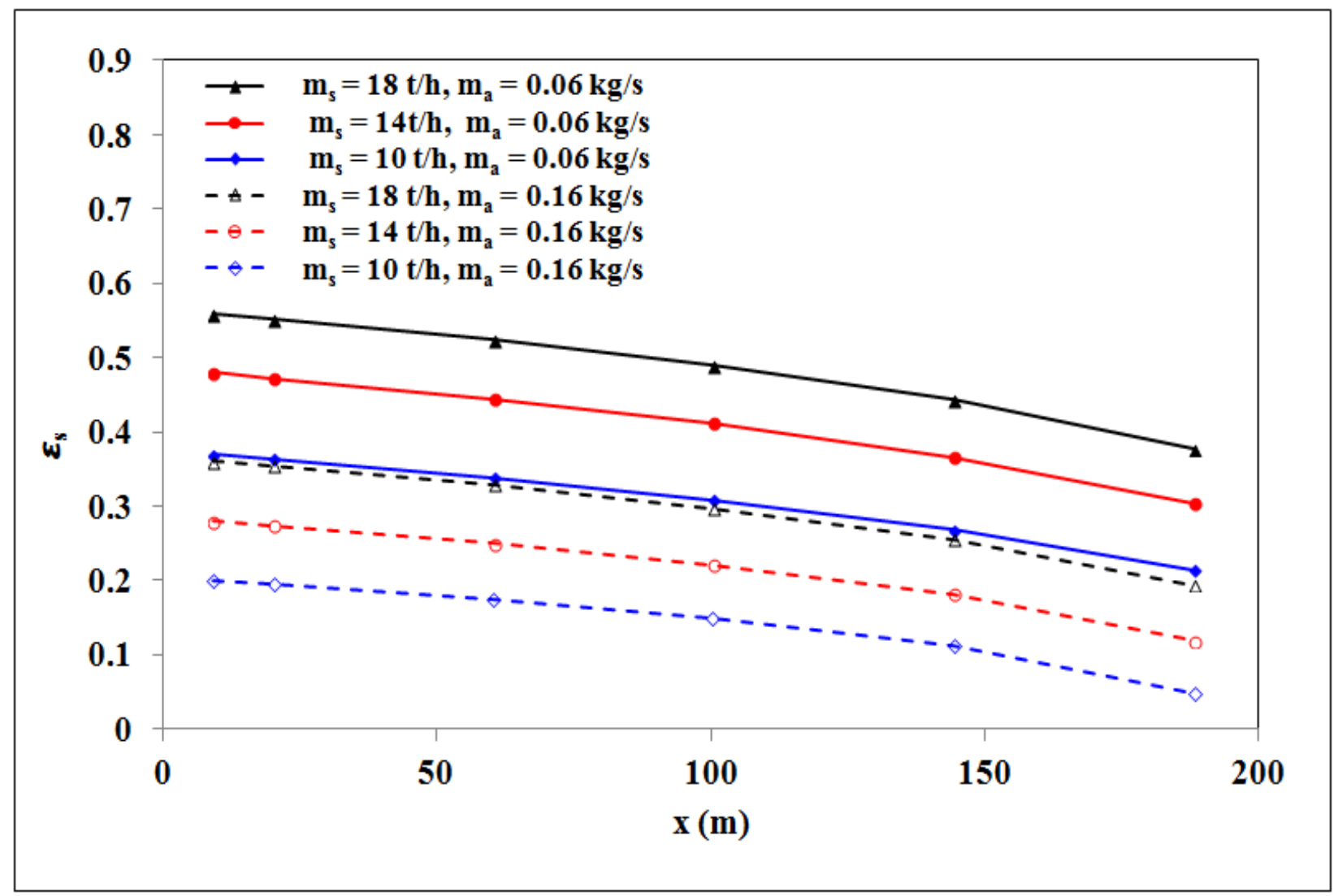

Figure 9: Variation of solids volumetric with respect to the spatial distance $(x)$ along the flow direction for different air flow rates $(0.06$ and $0.16 \mathrm{~kg} / \mathrm{s})$ and solids mass flow rates $(18,14$ and $10 \mathrm{t} / \mathrm{h})$. 


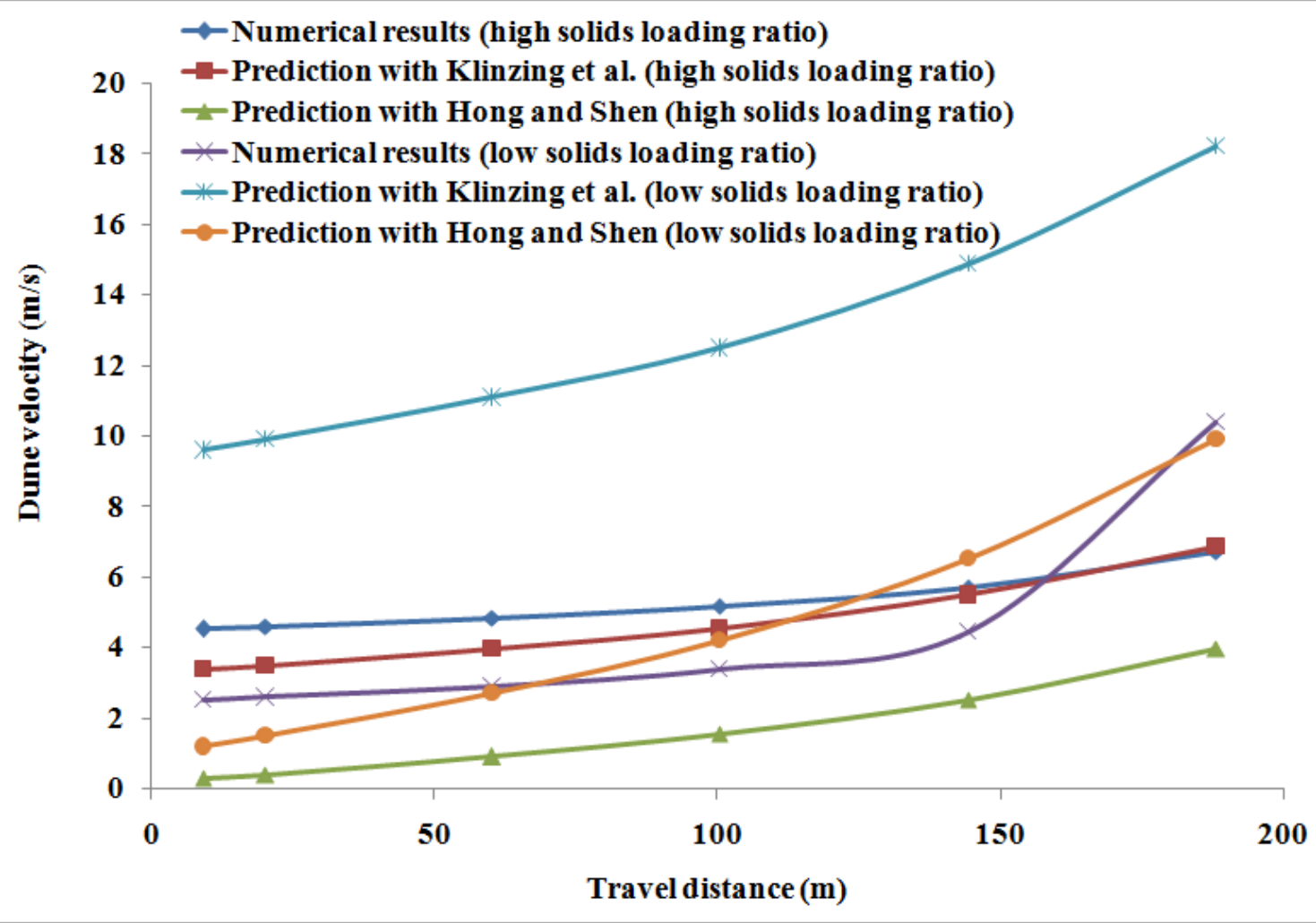

Figure 10: Comparison of prediction of dune velocity, numerical versus model predictions, $\mathrm{m}_{\mathrm{s}}=18 \mathrm{t} / \mathrm{h}, \mathrm{m}_{\mathrm{a}}=0.06 \mathrm{~kg} / \mathrm{s}$ (high solids loading ratio) and $\mathrm{m}_{\mathrm{s}}=10 \mathrm{t} / \mathrm{h}, \mathrm{m}_{\mathrm{a}}=0.16 \mathrm{~kg} / \mathrm{s}$ (low solids loading ratio) 


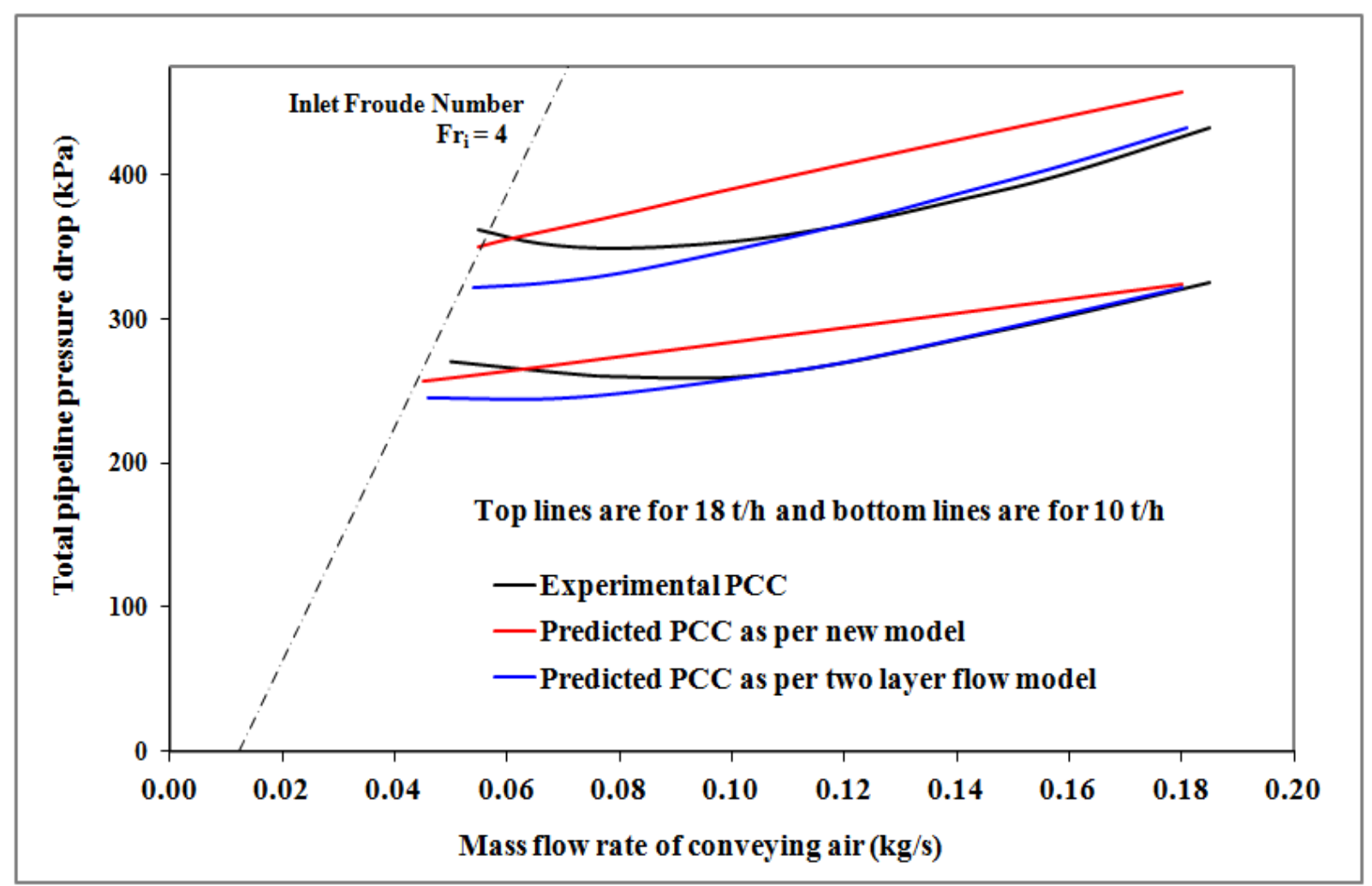

Figure 11: Scale-up evaluation for solids friction factor model

$$
\mathrm{D}=65 \mathrm{~mm}, \mathrm{~L}=254 \mathrm{~m}
$$




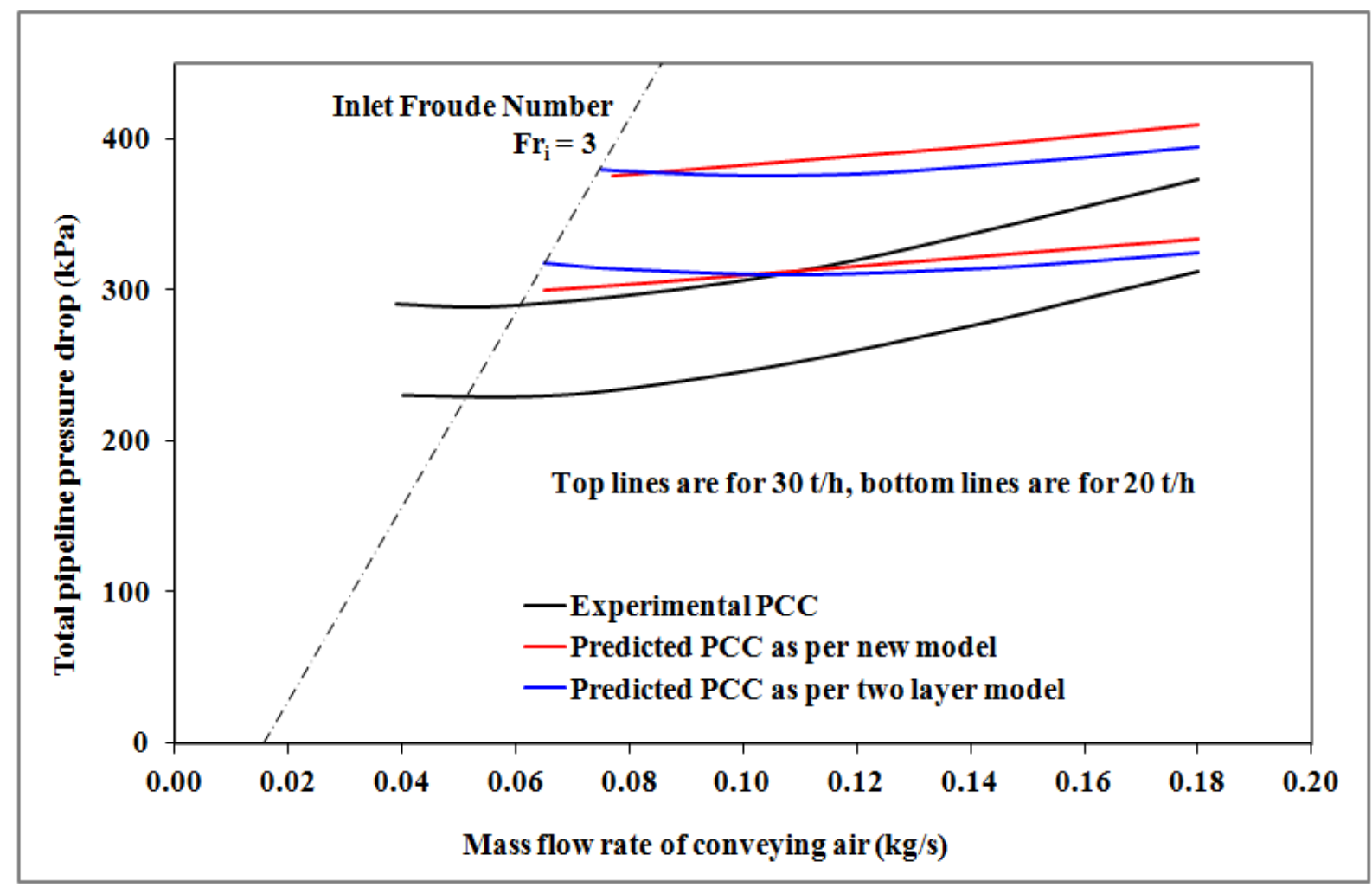

Figure 12: Scale-up evaluation for solids friction factor model

$$
\mathrm{D}=80 / 100 \mathrm{~mm}, \mathrm{~L}=407 \mathrm{~m}
$$


Table 1: Physical properties of the fly ash conveyed

\begin{tabular}{|l|l|c|c|c|c|c|}
\hline Product & Laboratory & $\begin{array}{c}\mathbf{d}_{\mathbf{5 0}} \\
(\boldsymbol{\mu m})\end{array}$ & $\begin{array}{c}\boldsymbol{\rho}_{\mathbf{s}} \\
\left(\mathbf{k g} / \mathbf{m}^{\mathbf{3}}\right)\end{array}$ & $\begin{array}{c}\mathbf{\rho}_{\mathbf{b}} \\
\left(\mathbf{k g} / \mathbf{m}^{\mathbf{3}}\right)\end{array}$ & $\begin{array}{c}\mathbf{D} \\
(\mathbf{m m})\end{array}$ & $\begin{array}{c}\mathbf{L} \\
(\mathbf{m})\end{array}$ \\
\hline \multirow{2}{*}{ Fly ash 1 } & Bulk Materials Handling, & 22 & 2370 & 660 & 65 & 254 \\
& Fujian Longking Co. & & & & $80 / 100$ & 407 \\
\hline
\end{tabular}


Table 2: Ratio of fluidized to loose-poured bulk densities for different fly ash samples

\begin{tabular}{|c|c|c|c|c|}
\hline \multirow{2}{*}{ Fly ash no. } & $\mathbf{d}_{\mathbf{5 0}}$ & $\boldsymbol{\rho}_{\mathbf{s}}$ & $\boldsymbol{\rho}_{\mathbf{b}}$ & \multirow{2}{*}{$\boldsymbol{\rho}_{\mathbf{f}} / \boldsymbol{\rho}_{\mathbf{b}}$} \\
\cline { 2 - 4 } & $(\boldsymbol{\mu m})$ & $\left(\mathbf{k g} / \mathbf{m}^{\mathbf{3}}\right)$ & $\left(\mathbf{k g} / \mathbf{m}^{\mathbf{3}}\right)$ & \\
\hline 1 & 22 & 2370 & 660 & 0.50 \\
\hline 2 & 69 & 2025 & 818 & 0.55 \\
\hline 3 & 53 & 2032 & 804 & 0.52 \\
\hline 4 & 41 & 2030 & 780 & 0.51 \\
\hline
\end{tabular}

